\title{
Kernos
}

Revue internationale et pluridisciplinaire de religion grecque antique

12| 1999

Varia

\section{F. Roscalla, Presenze simboliche dell'ape nella}

\section{Grecia antica}

\section{Pierre Somville}

\section{OpenEdition \\ Journals}

\section{Édition électronique}

URL : http://journals.openedition.org/kernos/739

DOI : $10.4000 /$ kernos.739

ISSN : 2034-7871

\section{Éditeur}

Centre international d'étude de la religion grecque antique

\section{Édition imprimée}

Date de publication : 1 janvier 1999

Pagination : 314-315

ISSN : 0776-3824

\section{Référence électronique}

Pierre Somville, «F. roscalla, Presenze simboliche dell'ape nella Grecia antica », Kernos [En ligne], 12 । 1999, mis en ligne le 13 avril 2011, consulté le 10 mars 2021. URL : http://journals.openedition.org/ kernos/739; DOI : https://doi.org/10.4000/kernos.739 
niales de Zeus. Significatives de la faiblesse du pouvoir de Zeus qu'il ne peut neutraliser qu'en s'appropriant la puissance d'entités féminines (Métis, Thémis, Eurynomé) auxquelles il s'unit, ces unions constituent la réelle prise de pouvoir de Zeus sur le royaume des cieux. Le même A. s'est attaché, dans le troisième chapitre, au cas particulier du mariage sacré entre Héra et Zeus, et avec Deméter, il aborde la problématique des liens unissant, en Grèce ancienne, alimentation, mariage, lois et ordre social, et de leur transposition dans les mythes les plus archaiques. Dans le chapitre suivant, il met en évidence les fondements mythiques de l'opposition entre les Muses et les Piérides qu'il interprète comme la lutte opposant les insectes aux oiseaux. Enfin, dans Mito e ideologia, F.J. Gonzalez García montre combien le mythe grec reflète l'idéologie de la société, où domine l'homme et où se soumet la femme.

C'est le héros qui est au centre de la seconde partie du livre; dans un chapitre introductif consacré au héros et au mythe, J.C. Bermejo Barrera élabore une typologie des héros grecs avant que soient abordés le cas des deux héros par excellence que sont Achille et Ulysse. F.J. Gonzalez García analyse les liens qu'Achille entretient avec l'idéologie indo-européenne; préférant une vie courte et valeureuse à une vie longue et pacifique, le héros de l'Iliade se conforme bien à l'idéal de la deuxième fonction telle que l'a définie Dumézil et, dans son conflit avec le pouvoir royal, il manifeste l'antagonisme de tradition indo-européenne entre première fonction et fonction guerrière. $S$. Reboreda Morillo rassemble les témoignages littéraires sur la vie d'Ulysse et montre que l'Ulysse de l'Iliade est bien l'homme caractérisé par sa métis qui sera le héros de l'Odyssée. Elle analyse ensuite le jeu subtil des relations que le héros entretient avec les principales divinités qui; dans l'Odyssée, décident de son destin.

L'ouvrage pêche par un manque d'homogénéité dans les questions abordées ainsi que par quelques négligences de présentation. On regrette l'absence de bibliographie et on ne saisit pas toujours quels critères ont présidé au choix des mots formant l'index. Néanmoins, ce livre est réellement novateur tant par les thèmes abordés que par ses perspectives.

Fabio Roscalla, Presenze simboliche dell'ape nella Grecia antica, Firenze, La Nuova Italia Editrice, 1998. 1 vol. $17 \times 24 \mathrm{~cm}, 148$ p. (Pubblicazioni della Facoltà di Lettere e Filosofia dell'Università di Pavia, 86). ISBN : 88-2212825-7.

Voici, de bout en bout, une remarquable thèse : bien construite, bien charpentée, bien menée. Après nous avoir rappelé le rôle, joué en filigrane, par la grotte, l'abeille et le rûcher dans la récurrence (ennéaétérique ?) du pouvoir royal évoqué par les mythes, anatolien et crétois, de Telepinu et de Minos, - et l'avoir restitué dans l'orbe traditionel de la mort et de la vie en leurs retours cycliques, l'A. envisage l'étrange proximité de l'abeille et des Sirènes qui bombinent pareil lement autour des prés fleuris. Leurs liens à la «bougonie » et au monde des morts les rassemble de manière assez convaincante, de même que le chant continu qui les caractérise induit au développement musical quant à l'origine des premiers instruments, essentiellement à vent. Considérant alors tout un pan mythologique, l'A. établit d'astucieux croisements béotiens et corinthiens noués autour des noms de Melissos, d'Actéon, d'Aristée et de Mélicerte. Passant enfin aux realia du miel sauvage, de l'essaim et de la ruche, tout en les confrontant aux autres réalités, mythiques et culturelles, il termine par une éclairante mise au 
point quant au problème du totémisme, si décrié de nos jours, et conclut à une forme de réhabilitation où l'onomastique retrouve heureusement tous ses droits.

Les meilleurs moments de ce travail habile et convaincant, bien qu'il semble parfois confiner à une sorte de "mélissomanie », sont assurément ceux où l'archéologie et la linguistique se rencontrent et se recoupent, malgré la disparité chronologique de nombreuses strates documentaires.

Cela dit, dans le cadre d'une bibliographie des plus abondantes et qui se voudrait exhaustive, je pointe quelques lacunes: je ne parlerai guère de mes propres travaux dont la diffusion a toujours été assez confidentielle ${ }^{1}$, mais ne puis m'empêcher de signaler l'absence de Charles Picard quand il s'agit des possibles origines crétoises de l'Oracle de Delphes, de Robert Laffineur à propos de l'orfèvrerie rhodienne ou de Silla Consoli à l'article des Sirènes ${ }^{2}$.

Mais en fait ces reproches sont véniels, car aucun des ouvrages que je viens de mentionner n'est de nature à infirmer gravement les propos de l'A. Ils les conforteraient plutôt dans le sens d'une approche symbolique de l'archaissme dont nous ne pouvons que le féliciter. J'ajoute qu'une référence aux considérations de Tolstoï (Guerre et Paix, $3^{\mathrm{e}}$ livre, $3^{\mathrm{e}}$ partie, chapitre 20) sur l'abandon de Moscou, placées sous le signe de la grandiose métaphore de la ruche dévastée, aurait pu venir éclairer latéralement certains propos de l'A., tout à fait pertinents dans leur résonance totémique ou dynastique.

Pierre Somville (Université de Liège)

Fabio Mora, Il pensiero storico-religioso antico. Autori greci e Roma l: Dionigi d'Alicarnasso, Roma, l'"Erma" di Bretschneider, 1995, XVIII+464 p. (Storia delle religioni, 12). ISBN : 88-7062-887-6.

Cet impressionnant volume est le premier d'une série qui, sous la direction de Ugo Bianchi et Giulia Piccaluga, se propose d'étudier «la pensée religieuse » de plusieurs historiens grecs et romains d'époque impériale. Le point de vue est résolument subjectiviste : ce n'est pas la valeur documentaire de ces textes historiographiques, ce ne sont pas les données objectives qu'ils transmettent sur les realia (rites, sacerdoces, panthéons, doctrines et croyances) qui intéressent au premier chef les initiateurs de ce projet, mais bien plutôt le travail de sélection, de classification, d'organisation, en un mot d'interprétation auquel chacun de ces historiens se livre à partir de la matière religieuse - à lui familière ou au contraire radicalement étrangère - dont son cuvre s'efforce de rendre compte, occasionnellement ou de façon systématique. L'ambition est, au-delà, de mettre en évidence le caractère traditionnel, convenu, ou à l'inverse, original, voire atypique, de la démarche adoptée par l'historien considéré, ce qui suppose non seulement une comparaison de ces historiens entre eux, mais aussi une reconstitution du contexte politique et culturel dans lequel ils ont vécu.

Fabio Mora avait déjà eu l'occasion d'expérimenter cette approche dans une précédente étude consacrée à Hérodote (Religione e religioni nelle Storie di Erodoto, Milano, 1986), auteur à cet égard exemplaire, puisqu'il décrit les réalités religieuses des peuples barbares de l'Asie en faisant constamment référence, quoique de manière généralement implicite, au modèle hellénique. L'idée d'étudier en-

1 Études grecques, Mardaga, Liège, 1990, dont le premier chapitre « L'abeille et le taureau »(p. 11-23) reprend le texte d'un article paru voici vingt ans déjà dans la Revue de l'Histoire des Religions.

2 Et non « Ensoli » (sic), p. 43 et 125 